\title{
PERFORMANCE OF TRICHOGRAMMA EVANESCENS WESTWOOD EGG PARASITOID AGAINST ANGOUMOIS GRAIN MOTH, SITOTROGA CEREALLELA. (OLIVIER)
}

\author{
T. AKTER \\ Department of Entomology, Sher-e-Bangla Agricultural \\ University, Dhaka-1207, Bangladesh.
}

\begin{abstract}
The performance of Trichogramma evanescens Westwood egg parasitoid against Angoumois grain moth, Sitotroga cereallela. (Olivier) was investigated during the period from January 2011 to May 2011. The results showed that the highest per cent of adult parasitoid emergence (98.94\%) from parasitized eggs of $S$. cerealella was by $T$. evanescens. The duration of adult parasitoid emergence varied from 7-8 days. The longevity of $T$. evanescens adult that emerged from parasitized eggs varied from 3-4 days. In consideration of rate of parasitization by using different number of parasitoids, the highest $(98.00 \%)$ parasite eggs were recorded from 50 pairs of parasitoids which was statistically identical $(94.25 \%)$ with 35 pairs and followed $(93.25 \%, 92.75 \%$ and $92.25 \%$ ) by 25,20 and 15 , pairs respectively. The rate of parasitism increased with increased number of parasitoids. A positive correlation exists between per cent parasitism and adult parasitoid emergence from parasitized eggs. It reveals that the $T$. evanescens has potential in the biological control of Angoumois grain moth, of $S$. cerealella.
\end{abstract}

Key words: Performance, Egg parasitoid, Trichogramma evanescens, Angoumois grain moth, Sitotroga cerealella

\section{Introduction}

Insect infestation on stored grains and their products is a serious problem throughout the world. Among the different species of storage pests, Angoumois grain moth, Sitotroga cereallela Olivier is common and most destructive. The insect shows its activity mainly in storage in Bangladesh, but also it's attacking activity starts from the field. A substantial amount of unhusked rice, wheat, joar, maize, bran etc. is stored at farmer's level which is badly damaged by Angoumois grain moth. So, it is necessary to control their populations in storage. At present different kinds of preventive and curative control measure are practiced to protect insect pests. Among them, chemical pesticides are being used for controlling the insect pests of different crops in Bangladesh. However, in spite of insect pest management many serious drawbacks of pesticide use was also noticed during this long period. Those include secondary pest outbreak, pest resurgence, toxic residue in food, soil, water and air, elimination of natural enemies, pest resistance etc. At the same time concern about human health and environmental quality has renewed the interest in integrated pest management programs that emphasize the biological control 
(Anonymous 1992) of insect pest. There are many biological control agents such as predators, parasitoids, micro-organisms which control the insect pests naturally. Specially parasitoids have a major impact in natural and ecosystem where they influence or regulate the population density of many of their hosts. In nature, parasitoid can be categorized as egg, larval and pupal parasitoid. Among them different species of Trichogramma are considered as the most important egg parasitoid especially for augmentation. Trichogramma and other egg parasitoids are generally part of the local ecosystem and often contribute to the control of Lepidopteran pests in absence of disruptive pesticides. Trichogramma spp are the tiny wasp belongs to the family Trichogrammatidae under the order Hymenoptera. Trichogramma spp are the most widely used insect enemy in the world (Waage and Ming 1984 and Li-Ying 1994). Trichogramma is a facultative gregarious (Rabinovich 1971) polyphagous egg parasitoid that often used in innundative biological control programs (Smith 1996) against a wide range of Lepidopterous eggs (Corrigan and Laing 1994).

Trichogramma are used against Helicoverpa armigera on a variety of crops in India and are effective biological control agent against the European corn borer Ostrinia nubilalis (Lepidoptera: Pyralidae) and they are also used to provide foliage protection in forests (Bai et al. 1995). Trichogramma spp can be used in rice pest management (Beevi et al. 2003). These are often used against Lepidopteran pest in stored grain, where Trichogramma evanescens and T. embryopaga attack Ephestia kuehniella and E. elutella (Scholler et al. 1996).

In most crop production system, the numbers of Lepidopteran pest eggs destroyed by native population of Trichogramma spp are not sufficient to prevent the pest from reaching the damaging level. So, mass rearing and consequent augmentation is necessary. Although worldwide Trichogramma spp have been considered as most important egg parasitoid for innundative biological agents but in Bangladesh very few works have so far been done on the mass rearing as well as its field efficacy. As this wasp occurs naturally in almost every terrestrial habitat and it can also be mass reared and released in the research field which may provide a great opportunity to use Trichogramma spp in an IPM package for the control of Lepidopteran pest including $S$. cerealella.

\section{Materials and Methods}

The present experiment was undertaken on performance of Trichogramma evanescens Westwood egg parasitoid against Angoumois grain moth, Sitotroga cereallela. (Olivier) in the laboratory of the Department of Entomology, Sher-e-Bangladesh Agricultural University, Dhaka-1207 during the period from January 2011 to May 2011. The experiment was carried out under laboratory conditions at room temperature of $24-32^{\circ} \mathrm{C}$ with relative humidity of $60-76$ per cent. The collected moths were enclosed in plastic jars/container (measuring $10 \times 12 \mathrm{inch}$ ) for mating and oviposition of the parasitoid. 
Collection of eggs of $S$. cerealella (host): For the collection of fresh egg mass, the rearing of $S$. cerealella was done by using wheat grain (only for rearing purposes) as a diet in a special mass rearing chamber. From $S$. cerealella mass rearing chamber, thousands of adults were collected and kept them in a glass cylinder. The top of the cylinder was covered by 32 mesh net. Adults were kept in a cylinder for one day for mating and subsequent egg laying on the glass cylinder. In the consecutive days the eggs laid on the wall of the cylinder were brushed and sieved to collect fresh eggs. Then the body parts of moth were cleaned and fresh eggs were obtained. The collected eggs were kept into a glass tube with labeling and stored in a refrigerator at $4^{0} \mathrm{C}$ temperature to ensure continuous supply for future study.

Collection of egg parasitoid Trichogramma evanescens Westwood: In the present study $T$. evanescens eggs were used in different purposes. It was also collected as pupae in container with labeling from Ispahani -Biotec. Dewaliabari, Konabari, Gazipur.

Prepation of eggs strips: Paper strips with host eggs were made to use in the experiment. For making the egg strips the following materials were used, i) paper strips $(10 \mathrm{X} 1 \mathrm{~cm})$ with labeling, ii) acasia powder (LAM), iii) distilled water, iv) small petridish (watch glass), and v) dropper. At first $10 \%$ acacia gum was prepared in a small petridish by mixing distilled water in acacia powder and distilled water.

Mixing of water was done very carefully with a dropper to maintain proper viscosity of the gum. So that it could hold the host eggs firmly with the paper strip. One hundred fresh eggs were kept on a paper sheet separately. In this way total of five (05) hundred eggs of host ( $S$. cerealella) were divided into 05 parts. To make the host strip, a small amount of acacia glue was taken by finger and carefully pressed in the front side of the labeled paper strip. Immediately previously counted 100 eggs were placed carefully on the glued portion of the paper strip. Then the eggs were spread on the glued portion of the strips very carefully. So that, there would be only one layer of eggs on the strip. After preparing the strips, these were labeled with date, host name, parasitoid name and number, and number of eggs per strip.

Parasitism efficacy of $T$. evanescens on host ( $S$. cerealella) eggs: The parasitism efficacy of $T$. evanescens was evaluated on host ( $S$. cerealella) eggs. For the parasitization, one host strip, containing 100 eggs and one parasitoid T. evanescens pupae strips (having 100 pupae of Trichogramma) were placed together in individual test tube. In this way egg strips were parasitized with $T$. evanescens. Then the test tubes containing one host egg strip (Fig. 1) and T. evanescens pair(s) were placed in the parasitization chamber (Fig. 2) after proper labeling with date, name and number of eggs and parasitoid respectively. In the parasitization chamber two third portions of the test tubes were covered by black cloths except the eggs which were placed for the parasitization as because in light the movement of $T$. evanescens was very frequent. 


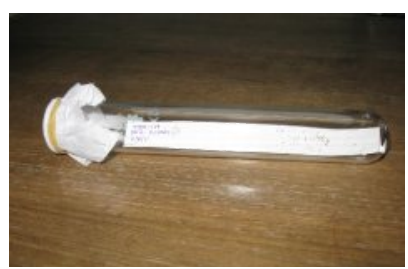

Fig. 1. Paper strip containing test tube with T. evanescens for parasitization.

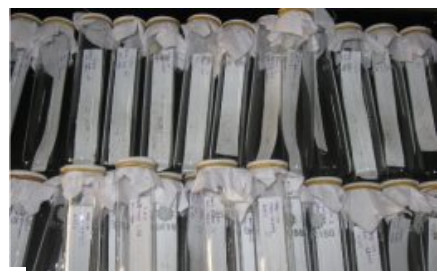

Fig. 2. Test tubes containing $T$. evanescens and host eggs of $S$. cerealella in the parasitic chamber

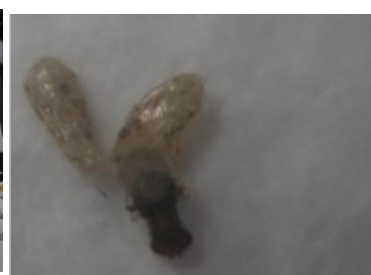

Fig. 3. T. evanescens parasitizing eggs of angoumois grain moth, S. cerealella
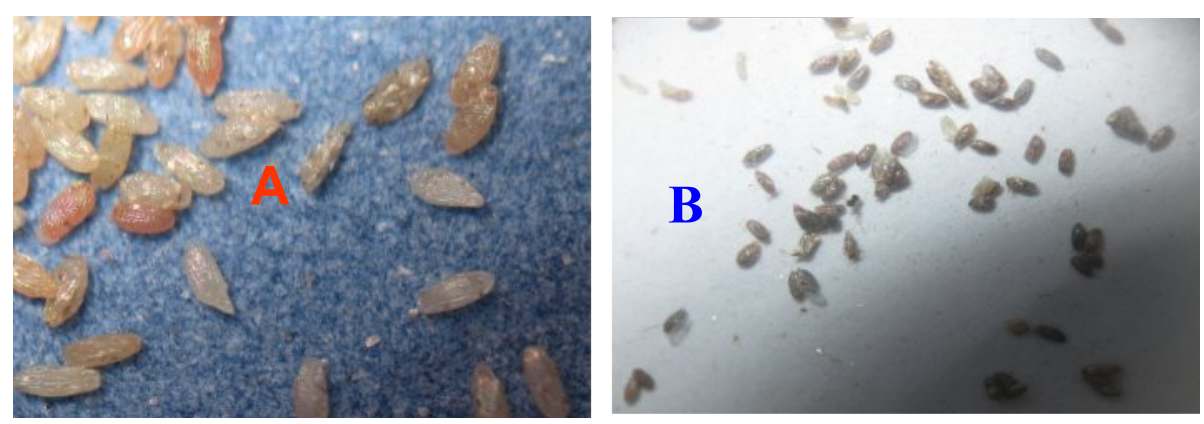

Fig. 4. Collected fresh eggs (A) and parasitized eggs B) of Angoumois grain moth, S. cerealella.

Data collection: Data for the experiment were collected on the following parameters: Percentage of egg parasitized; adult emergence from parasitized eggs; percentage of emergence of $T$. evanescens; time required for first emergence of $T$. evanescens; adult longevity of $T$. evanescens and total life span.

Rate of parasitization of $T$. evanescens on Sitotroga cerealella eggs (Keeping $S$. cerealella eggs fixed and parasitoid, T. evanescens variable): Effective host egg parasitism depends on the number of parasitoids. In this study T. evanescens was used for parasitization of the host. For the parasitization, host egg strip, containing 100 eggs of the host was exposed separately to nine different sets of $T$. evanescens adult pair's and each set was composed of $2,5,8,10,15,20,25,35$ and 50 pairs of adult parasitiod, respectively. Each host egg strip and desired number of parasitoids were placed together in a test tube with proper labeling. The experiment was replicated five times, and then all of the prepared test tubes placed in the parasitization chamber. 
Rate of parasitization of $T$. evanescens on $S$. cerealella eggs (on the basis of host eggs, $S$. cerealella variable and parasitoid, $T$. evanescens fixed): For parasitization, host egg strip, containing different categories number of eggs of the host were exposed separately to fixed 10 pairs of adult (randomly selected) T. evanescens. The numbers of eggs of the host categories were 50,100,120, 150, 180, 200 and 250. In that way 21 egg strips of the host with 5 replications were parasitized with 10 pairs (randomly selected) T. evanescens. The test tubes containing one host egg strip and 10 pairs of $T$. evanescens adults were then placed in the parasitization chamber after proper labeling with date, number of eggs, name of host and parasitoid.

The observed data were analyzed statistically following MSTAT program. The mean values were compared by Duncan Multiple Range Test at the 5\% level of probability (Gomez and Gomez 1984). Standard error of each parameter was calculated.

\section{Results and Discussion}

Parasitism efficacy of Trichogramma: Performance of $T$. evanescens egg parasitoid against angoumois grain moth, Sitotroga cerealella was evaluated with release 10 pairs of $T$. evanescens in 6 different Petri dish and recorded different number of parasitized eggs that varied from 70-100 with mean of 88.67 (Table 1). In consideration of adult emergence from parasitized eggs, it varied from 68 to 97 with an average of 83.33 and the highest (97) adult was recorded from 100 parasitized eggs and the lowest (68) from 70 of parasitized eggs. Period of $1^{\text {st }}$ emergence of $S$. cerealella varied from 7-8 days for different parasites eggs. The highest ( 8 days) period for $1^{\text {st }}$ emergence was recorded from 95 and 90 parasite eggs and the lowest ( 7 days) was recorded from the other eggs. The highest (98.94\%) adult emergence from parasitized eggs was recorded from 95 eggs and the lowest $(82.54 \%)$ was recorded from 84 eggs. Longevity of $T$. evanescens adult that emerged from parasitized eggs varied from 3-4 days with an average of 3.50 days and the highest (4 days) was recorded from 100, 90, 84 parasitized eggs and the lowest ( 3 days) was recorded from other parasites.

From the present study it was observed that an increasing trend of parasitism by the parasitoid, T. evanescens was observed up to 10 pairs of adult release on 100 eggs of $S$. cerealella. It was also observed from the study, a positive correlation present between the number of parasitoids with per cent parasitism and adult parasitoid emergence from parasitized eggs. 
Table 1. Parasitism efficacy of T. evanescens Westwood on eggs of angoumois grain moth, Sitotroga cerealella (Olivier).

\begin{tabular}{l|l|l|l|l|l}
\hline $\begin{array}{l}\text { Serial no. of Set } \\
\text { with host no. }\end{array}$ & $\begin{array}{l}\text { Parasites } \\
\text { eggs } \\
\text { (No.) }\end{array}$ & $\begin{array}{c}\text { Adult emergence } \\
\text { from parasitized } \\
\text { eggs }\end{array}$ & $\begin{array}{c}\text { Emergence } \\
\text { Period } \\
\text { (day) }\end{array}$ & $\begin{array}{l}\text { \%Adult } \\
\text { emergence from } \\
\text { parasitized eggs }\end{array}$ & $\begin{array}{l}\text { Adult } \\
\text { longevity }\end{array}$ \\
\hline Set:1 (100) & 100 & $97 \pm 1.83 \mathrm{a}$ & $7 \pm 0.00 \mathrm{~b}$ & $97.00 \pm 1.83 \mathrm{a}$ & $4 \pm 0.82 \mathrm{a}$ \\
Set:2 (100) & 95 & $94 \pm 3.65 \mathrm{a}$ & $8 \pm 0.82 \mathrm{a}$ & $98.94 \pm 3.84 \mathrm{a}$ & $3 \pm 0.00 \mathrm{~b}$ \\
Set:3 (100) & 93 & $88 \pm 2.45 \mathrm{~b}$ & $7 \pm 0.82 \mathrm{~b}$ & $94.62 \pm 2.63 \mathrm{a}$ & $3 \pm 0.00 \mathrm{~b}$ \\
Set:4 (100) & 90 & $86 \pm 4.24 \mathrm{~b}$ & $8 \pm 0.82 \mathrm{a}$ & $95.55 \pm 4.71 \mathrm{a}$ & $4 \pm 0.82 \mathrm{a}$ \\
Set:5 (100) & 84 & $70 \pm 3.56 \mathrm{c}$ & $7 \pm 0.00 \mathrm{~b}$ & $82.54 \pm 4.24 \mathrm{~b}$ & $4 \pm 0.82 \mathrm{a}$ \\
Set:6 (100) & 70 & $68 \pm 2.58 \mathrm{c}$ & $7 \pm 0.00 \mathrm{~b}$ & $97.14 \pm 3.69 \mathrm{a}$ & $3 \pm 0.00 \mathrm{~b}$ \\
LSD $_{(0.05)}$ & -- & 4.698 & 0.857 & 5.384 & 0.857 \\
Level of & -- & 0.01 & & 0.01 & 0.05 \\
Significance & -- & 3.77 & 0.05 & & 16.50 \\
CV(\%) & -- & 7.87 & 3.84 & \\
\hline
\end{tabular}

In a column means having dissimilar letter(s) differ significantly at 0.05 level of probability and numeric data represent the mean value of 5 replications.

The performance of $T$. evanescens egg parasitoid against angoumois grain moth, $S$. cerealella obtained in the present investigation is in agreement with the results obtained by Alam et al. (2008a), Brower (1983), El-Waakeil (2007), Hasan and WenQing (2001), Alam et al. (2008b), Corrigan and Laing (1994), Doylon and Boivin (2005) and Strand (1986). Alam et al. (2008a) reported that significantly highest egg parasitism occurred in T. evanescens $(88.6 \%)$ than other species viz. T. chilonis $(77.6 \%)$ and $T$. japonica $(43.8 \%)$ when reared on host eggs of $S$. cerealella.

Innundative release of $T$. evanescens adults into commodity could play an important role in suppression of Lepidopterous moth populations (Brower 1983) especially $S$.cerealella (Alam et al. 2008a, El-Waakeil 2007, Hasan and WenQing 2001) and Corcyra cephalonica (Alam et al. 2008a and 2008b).

According to Corrigan and Laing (1994) and Doylon and Boivin (2005), T. evanescens are ployphagous egg parasitoids that are often used against a wide range of Lepidopterous eggs that are totally eco- friendly and non-toxic to the consumers.

Rate of parasitization: Rate of parasitization was recorded by using 100 eggs of $S$. cerealella with different pairs of the parasitoids. In case of number of parasite eggs, the highest number (98.00) of parasitized eggs were recorded from 50 pairs of parasitoids which was statistically identical (94.25) with 35 pairs and followed $(93.25,92.75$ and 92.25 ) by 25,20 and 15, pairs respectively (Table 2). On the other hand, the lowest number (53.00) of parasite eggs were recorded from 2 pairs of parasitoid which was followed (63.25) by 5 pairs of parasitoids. In case of adult emergence from parasitized eggs, the highest (96.25) was recorded from 50 pairs of parasitoids and lowest (51.00) was recorded from 2 pairs of parasitoids. In consideration of rate of parasitization by 
using different number of parasitoids, the highest (98.00\%) parasite eggs were recorded from 50 pairs of parasitoids which was statistically identical $(94.25 \%)$ with 35 pairs and followed $(93.25 \%, 92.75 \%$ and $92.25 \%)$ by 25,20 and 15, pairs respectively. Again, the lowest $(53.00 \%)$ parasite eggs were recorded from 2 pairs parasitoid followed $(63.25 \%)$ by 5 pairs of parasitoid.

Table 2. Rate of parasitization of $S$. cerealella eggs by $T$. evanescens in laboratory (On the basis of host eggs, $S$. cerealella is fixed and parasitoid, T. evanescens are variable).

\begin{tabular}{c|c|c|c|c}
\hline Serial No. & $\begin{array}{c}\text { No. of } \\
\text { parasitoids } \\
\text { (pairs) }\end{array}$ & $\begin{array}{c}\text { No. of parasitized } \\
\text { eggs }\end{array}$ & $\begin{array}{c}\text { Adults } \\
\text { (parasitoid) } \\
\text { emergence from } \\
\text { parasitized eggs }\end{array}$ & $\begin{array}{c}\text { Rate of } \\
\text { parasitization (\%) }\end{array}$ \\
\hline 01 & 2 & $53.00 \pm 2.45 \mathrm{e}$ & $51.00 \pm 0.82 \mathrm{e}$ & $53.00 \pm 2.45 \mathrm{e}$ \\
02 & 5 & $63.25 \pm 2.06 \mathrm{~d}$ & $61.75 \pm 5.38 \mathrm{~d}$ & $63.25 \pm 2.06 \mathrm{~d}$ \\
03 & 8 & $87.25 \pm 2.87 \mathrm{c}$ & $84.25 \pm 3.69 \mathrm{c}$ & $87.25 \pm 2.87 \mathrm{c}$ \\
04 & 10 & $91.50 \pm 1.73 \mathrm{bc}$ & $90.50 \pm 4.93 \mathrm{~b}$ & $91.50 \pm 1.73 \mathrm{bc}$ \\
05 & 15 & $92.25 \pm 1.71 \mathrm{~b}$ & $89.75 \pm 4.57 \mathrm{~b}$ & $92.25 \pm 1.71 \mathrm{~b}$ \\
06 & 20 & $92.75 \pm 2.22 \mathrm{~b}$ & $92.25 \pm 1.26 \mathrm{ab}$ & $92.75 \pm 2.22 \mathrm{~b}$ \\
07 & 25 & $93.25 \pm 4.50 \mathrm{~b}$ & $92.75 \pm 2.99 \mathrm{ab}$ & $93.25 \pm 4.50 \mathrm{~b}$ \\
08 & 35 & $94.25 \pm 3.30 \mathrm{ab}$ & $91.25 \pm 1.89 \mathrm{ab}$ & $94.25 \pm 3.30 \mathrm{ab}$ \\
09 & 50 & $98.00 \pm 1.41 \mathrm{a}$ & $96.25 \pm 2.50 \mathrm{a}$ & $98.00 \pm 1.41 \mathrm{a}$ \\
$\mathrm{LSD}(0.05)$ & -- & 3.823 & 5.043 & 3.823 \\
Level of & -- & 0.01 & 0.01 & 0.01 \\
Significance & -- & 3.10 & 4.17 & 3.10 \\
CV(\%) & & & & \\
\hline
\end{tabular}

In a column means having dissimilar letter(s) differ significantly at 0.05 level of probability and numeric data represent the mean value of 5 replications.

Efficacy of the parasitoid: Efficacy of the parasitoid T. evanescens on the different number of $S$. cerealella (Olivier) eggs was determined by using 10 pairs parasitoids. The highest number of parasite eggs (192.0) was recorded from 250 host eggs which was statistically similar (173.75) with 200 host eggs and followed (149.25 and 138.0) by 180 and 150 number of host eggs. On the other hand, the lowest number of parasite eggs (48.25) was recorded from 50 host eggs which was followed (92.25 and 107.0) by 100 and 120 number of host eggs (Table 3). In consideration of adult emergence from parasitized eggs, the highest number (176.0) of adult emerged from parasitized eggs recorded from 250 host eggs, while the lowest (46.75) adult emerged from 50 parasitized host eggs. In the context of \% parasitoid emergence, the highest $(98.97 \%)$ was recorded from 100 host eggs which was statistically similar $(96.783 \%, 96.61 \%$ and $92.49 \%)$ to 50 , 150 and 120 number of host eggs, whereas the lowest (87.44\%) parasitoid emergence from 200 number of host eggs which was statistically similar (89.26\% and $91.81 \%)$ to 180 and 250 number of host eggs (Table 3 ). 
Table 3. Efficacy of the parasitoid T. evanescens Westwood on the different number of $S$. cerealella (Olivier) eggs.

\begin{tabular}{c|c|c|c}
\hline $\begin{array}{c}\text { No. of host }(S . \\
\text { cerealella) eggs }\end{array}$ & $\begin{array}{c}\text { Number of } \\
\text { Parasitized eggs }\end{array}$ & $\begin{array}{c}\text { Adults (parasitoids) } \\
\text { emergence from } \\
\text { parasitized eggs }\end{array}$ & $\begin{array}{c}\text { Parasitoid emergence } \\
\text { (\%) }\end{array}$ \\
\hline 50 & $48.25 \pm 2.06 \mathrm{~g}$ & $46.75 \pm 3.75 \mathrm{f}$ & $96.78 \pm 3.63 \mathrm{a}$ \\
100 & $92.25 \pm 2.06 \mathrm{f}$ & $91.25 \pm 3.30 \mathrm{e}$ & $98.97 \pm 4.74 \mathrm{a}$ \\
120 & $107.0 \pm 5.72 \mathrm{e}$ & $98.75 \pm 0.50 \mathrm{~d}$ & $92.49 \pm 5.00 \mathrm{ab}$ \\
150 & $138.0 \pm 8.16 \mathrm{~d}$ & $132.75 \pm 8.30 \mathrm{c}$ & $96.61 \pm 10.33 \mathrm{a}$ \\
180 & $149.25 \pm 7.76 \mathrm{c}$ & $133.00 \pm 2.45 \mathrm{c}$ & $89.26 \pm 4.02 \mathrm{~b}$ \\
200 & $173.75 \pm 3.77 \mathrm{~b}$ & $151.00 \pm 7.44 \mathrm{~b}$ & $87.44 \pm 2.37 \mathrm{~b}$ \\
250 & $192.00 \pm 6.53 \mathrm{a}$ & $176.00 \pm 4.90 \mathrm{a}$ & $91.81 \pm 5.68 \mathrm{~b}$ \\
& 8.337 & 7.450 & 8.270 \\
$\mathrm{LSD}_{(0.05)}$ & 0.01 & 0.01 & 0.05 \\
$\mathrm{Level}_{\text {of Significance }}$ & 4.41 & 4.27 & 5.13 \\
\hline $\mathrm{CV}(\%)$
\end{tabular}

In a column means having similar letter(s) are statistically identical and those having dissimilar letter(s) differ significantly at 0.05 level of probability and numeric data represent the mean value of 5 replications.

Strand (1986) reported that under laboratory conditions a female parasitizes from one to ten host eggs per day during her life. Large females parasitize more eggs than smaller ones.

Sergey et al. (2009) reported that total cumulative percentage of parasitizing females reached a maximum $(60 \%)$ at temperatures of $25-30^{\circ} \mathrm{C}$, while at 12 and $35^{\circ} \mathrm{C}$, respectively, 25 and $50 \%$ of females parasitized the $S$. cerealella eggs.

Although, in the present investigation, the performance of $T$. evanescens egg parasitoid against angoumois grain moth, $S$. cerealella may differ from those of the other workers, it is logical because the wasps lay their eggs within pest eggs and kill them. So, environmental friendly Trichogramma can be used to manage different types of pest species including $S$. cerealella as an egg parasitoid.

\section{References}

Alam, S.N., Mondal, M.F. and Nabi, M. 2008a. Parasitism efficacy of three Trichogramma spp. on two hosts eggs, Sitotroga cerealella and Corcyra cephalonica. Entomology Report 20072008. Bangladesh Agricultural Research Institute, Gazipur, Bangladesh. pp.14-15.

Alam, S.N., Mondal, M.F. and Nabi, M. 2008b. Optimization of number of Trichogramma for effective host egg parasitism. Entomology Report 2007-2008. Bangladesh Agricultural Research Institute, Gazipur, Bangladesh. pp.15-17.

Anonymous 1992: Statistical Year Book of Bangladesh. Bangladesh Bureau of Statistics, Statistics Division, Ministry of Planning, Government of the People's Republic of Bangladesh. pp. $108-112$.

Bai, B., Cobanoglu, S. and Smith, S.M. 1995. Assessment of Trichogrammma species for biological control of forest lepidopteran defoliators. Entomologia Experimentalis et. Applicata, 75:135 - 143 . 
Bai,B., Luck, R.F., Foster, L. Stephens, B. and Janssen, J.A.M. 1992. The effect of host size on quality attributes of the egg parasitoid, Trichogramma pretiosum. Entomologia Experimentalis et Applicata, 64:37 - 48.

Beevi, S.P., K.R. Lata and R.J. Rabindra. 2003: Impact of the inundative release of egg parasitoid, Trichogramma spp in rice pest management. Biological control of lepidopteran pests. Procedings of the Symposium of Biological Control of Lepidopteran pests. pp. 329 332.

Brower, J. H. 1983. Eggs of stored-product Lepidoptera as hosts for Trichogramma evanescens (Hymenoptera: Trichogrammatidae). Bio Control. 28 (4): 355 -361.

Corrigan, J. E. and Laing, J. E. 1994. Effects of the rearing host species and the host species attacked on performance by Trichogramma minutum Riley (Hymenoptera: Trichogrammatidae). Biological Control. 23: 755-760.

Doylon, J. and Boivin, J. 2005. The effect of development time on the fitness of female Trichogramma evanescens. Journal of insect science. 5(4): 5.

El-Waakeil, N. 2007. Evaluation of efficacy of Trichogramma evanescens reared on different facilitious hosts to control Helicoverpa armigera. J. Pest Sci. 80 (1): 29 - 34.

Gomez, A. C. and Gomez A. A. 1984. Statistical Procedure for Agricultural Research (2 ${ }^{\text {nd }}$ Edn.). Jhonwiley and Sons, New York. P. 680.

Hassan, S. A. and WenQing, Z. 2001. Variability in quality of Trichogramma brassicae (Hymenoptera: Trichogrammatidae) from commercial supplies in Germany. Biological Control. 22 (2): 115 - 121.

Li, Li-Ying 1994. Worldwide use of Trichogramma for biological control on different crops: A survey. In: Biological Control with Egg Parasitoids, (eds. E. Wajnberg and S. A. Hassan). Oxon, U.K., Cab International. J. Asia Pacific Entomol. 3 (2) 65 - 70.

Rabinovich, J.E. 1971. Population dynamics of Telenomus fariai (Hymenoptera: Scelionidae), a parasite of Chaga's disease vector. Revista de Biologia Tropical. 19: $109-120$.

Ramesh, L., D.N. Vaidya and Mehta, P.K. 2000: Relative abundance and extent of losses in unhusked rice due to stored grain insect pests in Kangra district of Himachal Pradesh. Pest-Management and Economic Zoology. 8 (2) 129 - 132.

Scholler, M., Hassan, S. A. and Reichmuth, C. 1996. Efficacy assessment of Trichogramma evanescena and T. embryophagum (Hymenoptera: Trichogrammatidae) for control of stored products moth pests in bulk wheat. Entomophaga. 41:125 - 132 .

Sergey, Y.R., Natalia, D.V., Nina P.V. 2009. Effect of temperature on the reproduction and development of Trichogramma buesi (Hymenoptera: Trichogrammatidae). European. J. Entomol. 12(2): 23 -28.

Smith, S.M. 1996: Biological control with Trichogramma: Advance, successes, and potential of their use. Ann. Rev. Entomol. 41375 - 406.

Strand, M. R. 1986. Physiological interactions of parasitoids and hosts. In: Insect parasitoids (eds. J. Waage and D Greathead), Academic Press, London. pp. $109-118$.

Waage, J. K. and Ming, N. G. S. 1984. The reproductive strategy of a parasitic wasp. Optimal progeny and sex allocation in Trichogramma evanescens. Journal of Animal Ecology. 53:401- 415 